\title{
Article \\ Shikonin Derivatives from Onsoma visianii Decrease Expression of Phosphorylated STAT3 in Leukemia Cells and Exert Antitumor Activity
}

\author{
Zeljko Todorovic ${ }^{1}$, Jelena Milovanovic ${ }^{2,3}$, Dragana Arsenijevic ${ }^{2,4} \oplus$, Nenad Vukovic ${ }^{5}$, Milena Vukic ${ }^{5}$, \\ Aleksandar Arsenijevic ${ }^{2}$, Predrag Djurdjevic ${ }^{1}$, Marija Milovanovic ${ }^{2, *}$ and Nebojsa Arsenijevic ${ }^{2}$ \\ 1 Department of Internal Medicine, Faculty of Medical Sciences, University of Kragujevac, \\ 34000 Kragujevac, Serbia; todorovic_zeljko@hotmail.com (Z.T.); pdjurdjevic@sbb.rs (P.D.) \\ 2 Center for Molecular Medicine and Stem Cell Research, Faculty of Medical Sciences, University of Kragujevac, \\ 34000 Kragujevac, Serbia; jelenamilovanovic205@gmail.com (J.M.); menki@hotmail.rs (D.A.); \\ aleksandar@medf.kg.ac.rs (A.A.); arne@medf.kg.ac.rs (N.A.) \\ 3 Department of Histology and Embriology, Faculty of Medical Sciences, University of Kragujevac, \\ 34000 Kragujevac, Serbia \\ 4 Department of Pharmacy, Faculty of Medical Sciences, University of Kragujevac, 34000 Kragujevac, Serbia \\ 5 Department of Chemistry, Faculty of Science, University of Kragujevac, 34000 Kragujevac, Serbia; \\ nvukovic@kg.ac.rs (N.V.); milena.vukic@kg.ac.rs (M.V.) \\ * Correspondence: marijaposta@gmail.com; Tel.: +381-34306800
}

Citation: Todorovic, Z.; Milovanovic, J.; Arsenijevic, D.; Vukovic, N.; Vukic, M.; Arsenijevic, A.; Djurdjevic, P.; Milovanovic, M.; Arsenijevic, N. Shikonin Derivatives from Onsoma visianii Decrease Expression of Phosphorylated STAT3 in Leukemia Cells and Exert Antitumor Activity. Nutrients 2021, 13, 1147. https:// doi.org/10.3390/nu13041147

Academic Editors: Raffaella Canali and Fausta Natella

Received: 28 February 2021

Accepted: 24 March 2021

Published: 31 March 2021

Publisher's Note: MDPI stays neutral with regard to jurisdictional claims in published maps and institutional affiliations.

Copyright: (c) 2021 by the authors. Licensee MDPI, Basel, Switzerland. This article is an open access article distributed under the terms and conditions of the Creative Commons Attribution (CC BY) license (https:// creativecommons.org/licenses/by/ $4.0 /)$

\begin{abstract}
Antitumor effects of shikonins on chronic lymphocytic leukemia (CLL) and B-cell prolymphocytic leukemia (B-PLL) are mostly unexplored. The antitumor activity of shikonins, isolated from Onosma visianii Clem (Boraginaceae), in BCL1, mouse CLL cells and JVM-13, human B-PLL cells was explored in this study. The cytotoxicity of shikonin derivatives was measured by an MTT test. Cell death, proliferation, cell cycle, and expression of molecules that control these processes were analyzed by flow cytometry. Expression of STAT3-regulated genes was analyzed by real-time q-RT-PCR (Quantitative Real-Time Polymerase Chain Reaction). The antitumor effects of shikonin derivatives in vivo were analyzed, using flow cytometry, by detection of leukemia cells in the peripheral blood and spleens of mice intravenously injected with BCL1 cells. The two most potent derivatives, isobutyrylshikonin (IBS) and $\alpha$-methylbutyrylshikonin (MBS), induced cell cycle disturbances and apoptosis, inhibited proliferation, and decreased expression of phospho-STAT3 and downstream-regulated molecules in BCL1 and JVM-13 cells. IBS and MBS decreased the percentage of leukemia cells in vivo. The link between the decrease in phosphorylated STAT3 by MBS and IBS and BCL1 cell death was confirmed by detection of enhanced cell death after addition of AG490, an inhibitor of Jak2 kinase. It seems that IBS and MBS, by decreasing STAT3 phosphorylation, trigger apoptosis, inhibit cell proliferation, and attenuate leukemia cell stemness.
\end{abstract}

Keywords: isobutyrylshikonin; $\alpha$-methylbutyrylshikonin; Onosma visianii; STAT3; BCL1; JVM-13

\section{Introduction}

Shikonin, a natural naphthoquinone pigment, first isolated from Lithospermum erythrorhizon, a Chinese herbal plant, was used for thousands of years in traditional Chinese medicine [1]. Recently, shikonin and its derivatives, have been isolated from the root of Onosma visianii Clem (Boraginaceae), a biennial to perennial plant and an inhabitant of the Balkan Peninsula and Southeast Europe [2]. Anti-inflammatory, antimicrobial, antioxidant, antitumor, and tissue reparative activities of shikonins have been reported [2,3]. Biological activities of shikonins are mediated by several molecules, including signal transducer and activator of transcription 3 (STAT3) [3]. STAT3, by relaying signals from activated growth and cytokine receptors in the plasma membrane to the nucleus, regulates the expression of numerous genes that control cell proliferation, differentiation, apoptosis, self-renewal, 
angiogenesis, and immune response, which collectively contribute to malignant transformations [4]. Constitutive activity of STAT3 has been reported in a variety of hematopoietic and solid malignancies including chronic lymphocytic leukemia (CLL) [5]. It has been reported that STAT3 inhibition induces tumor cell death and increases apoptosis of tumor cells by increasing the Bax/Bcl-2 ratio [6]. High expressions of stem-cell-specific molecules (Oct4, Nanog, and Sox2) regulated by STAT3 have been reported in several malignancies and are accompanied with the stem phenotype of cancer cells [7].

The incidence of CLL in Eastern Europe and North America is approximately 4.7 per 100,000 people per year, while, in the population over 85 years of age, the CLL incidence is higher than 35 [8]. The use of novel targeted therapies, like Bruton tyrosine kinase inhibitors and inhibitors of Bcl2 family proteins, have improved the prognosis of CLL patients, including elderly patients and those with poor risk features [9]. However, CLL is still an incurable and progressive disease. Stimulation of the B-cell receptor (BCR) in CLL cells leads to phosphorylation of STAT3, indicating STAT3 as a novel target for therapeutic intervention in CLL [10]. B-cell prolymphocytic leukemia (B-PLL) is, like CLL, a chronic lymphoproliferative disorder but with a much lower incidence, accounting for less than $1 \%$ of mature B cell malignancies [11]. Initially described as a variant of CLL [12], B-PLL was firstly recognized as a distinct mature B cell entity in the World Health Organization classification in 2008 [11]. B-cell prolymphocytic leukemia is a malignancy that is common in the elderly [13] and is an incurable disease with an even lower survival rate than CLL.

Antibacterial as well as cytotoxic activities against human colorectal and breast cancer cell lines of seven shikonin derivatives isolated from Onosma visianii (deoxyshikonin, isobutyrylshikonin (IBS), $\alpha$-methylbutyrylshikonin (MBS), acetylshikonin, $\beta$-hydroxyisovalerylshikonin, 5,8-O-dimethyl IBS and 5,8-O-dimethyl deoxyshikonin) have recently been reported [2]. However, the mechanism of cytotoxic activity has not been reported. The aim of this study was to explore the antitumor activity of these shikonin derivatives in murine BCL1 chronic lymphocytic leukemia cells and in human JVM-13 B-cell prolymphocytic leukemia to delineate a possible mechanism of action.

\section{Materials and Methods}

\subsection{Chemicals}

Shikonin derivatives were isolated and purified from Onosma visianii as previously described [2]. For in vitro experiments, all derivatives were first dissolved in dimethyl sulfoxide (DMSO) (Sigma-Aldrich) in such a way that the final concentration of DMSO in the medium was never greater than $0.5 \%$. For in vivo research, derivatives were dissolved in olive oil. Cyclophosphamide (Sigma-Aldrich, Saint Louis, MO,USA) was used as control substances for in vivo experiments.

\subsection{Cell Line}

A BCL1 mouse CLL cell line and a JVM-13 human B-PLL cell line were obtained from the American Type Culture Collection (ATCC-LGC, Wesel, Germany). BCL1 cells were cultured in RPMI 1640 supplemented with $2 \mathrm{mM}$ glutamine, $0.05 \mathrm{mM}$ 2-2-mercaptoethanol, 100 units $/ \mathrm{mL}$ penicillin, $100 \mu \mathrm{g} / \mathrm{mL}$ streptomycin, and $15 \%$ fetal bovin serum (FBS). JVM13 cells were cultured in RPMI 1640 with $2 \mathrm{mM}$ glutamine, 100 units/mL penicillin, $100 \mu \mathrm{g} / \mathrm{mL}$ streptomycin, and $10 \%$ FBS. All cells were grown in a $5 \% \mathrm{CO}_{2}$ incubator with standard conditions.

\subsection{MTT Assay}

A $6 \times 10^{3}$ cells/well was seeded in a 96-well plate, and $100 \mu \mathrm{L}$ solutions of different naphthoquinone compounds were added in final concentrations from $0.5 \mu \mathrm{g} / \mathrm{mL}$ to $100 \mu \mathrm{g} / \mathrm{mL}$. At the end of 24 or $48 \mathrm{~h}$ treatment, MTT (3-(4,5-dimethylthiazol-2-yl)-2,5diphenyltetrazolium bromide) solution $(5 \mathrm{mg} / \mathrm{mL})$ was added to each well and incubated for an additional $4 \mathrm{~h}$. The absorbance was measured at $595 \mathrm{~nm}$ using a Zenyth $3100 \mathrm{mi}-$ 
croplate multimode detector. Cell viability was measured as the percent ratio of absorbance in shikonin-derivative-treated cells over the control.

\subsection{Assessment of Cell Death by Flow Cytometry}

After treatment with IBS and MBS for $24 \mathrm{~h}$ at concentrations of $1 \mu \mathrm{g} / \mathrm{mL}$ and $2 \mu \mathrm{g} / \mathrm{mL}$, BCL1 and JVM-13 cells were stained with Annexin V-FITC and propidium iodide (PI) (BD Pharmingen, San Diego, CA, USA) according to the manufacturer's instructions. The percentages of late and early apoptotic cells were determined using a FACSCalibur flow cytometer (BD Biosciences, San Jose, CA, USA), and the data were analyzed using FlowJo (Tree Star).

\subsection{Cell Cycle Analysis}

After $24 \mathrm{~h}$ treatment with IBS and MBS at concentrations of $1 \mu \mathrm{g} / \mathrm{mL}$ and $2 \mu \mathrm{g} / \mathrm{mL}$, BCL1 and JVM-13 cells were stained with Vybrant ${ }^{\circledR}$ DyeCycle ${ }^{\mathrm{TM}}$ Ruby stain according to the manufacturer's instructions. Cell cycle distribution was analyzed by the FACSCalibur flow cytometer (BD Biosciences, San Jose, CA, USA), and the data were processed using FlowJo (Tree Star).

\subsection{Flow Cytometric Analysis}

BCL1 and JVM-13 cells, after IBS and MBS treatment for $24 \mathrm{~h}$, were fixed, permeabilized, and incubated with antibodies specific for Tyr 705 phosphorylated STAT3 (sc-8059, $200 \mu \mathrm{g} / \mathrm{mL}$, Santa Cruz Biotech. Inc., Santa Crus CA, USA, dilution 1:300) and Ki-67 (115698-82, $100 \mu \mathrm{g} / \mathrm{mL}$, eBioscience, San Diego, CA, USA, dilution 1:400). JVM-13 cell were stained with anti-cyclin D3 (ab28283, $100 \mu \mathrm{g} / \mathrm{mL}$, Abcam Cambridge, UK, dilution 1:100) antibody. BCL1 cells were stained with anti-p21 (ab188224, $100 \mu \mathrm{L}$, Abcam Cambridge, UK, dilution 1:50), anti-p16 (ab211542, $100 \mu \mathrm{L}$, Abcam Cambridge, UK, dilution 1:500), and anti-27 antibodies (ab215434, $100 \mu \mathrm{L}$, Abcam Cambridge, UK, dilution 1:100). Cells were additionally incubated with secondary goat anti-mouse IgG FITC (ab6717-1, $1 \mathrm{mg} / \mathrm{mL}$, Abcam Cambridge, UK, dilution 1:2000). The FACSCalibur flow cytometer (BD Biosciences, San Jose, CA, USA) was used for flow cytometric analysis, and the data were analyzed using FlowJo (Tree Star).

\subsection{Immunofluorescence Staining}

The expression of Bax and cleaved caspase- 3 proteins was investigated by the immunofluorescence method. The BCL1 cells were seeded in a 6-well plate and exposed to MBS at a concentration of $2 \mathrm{mg} / \mathrm{mL}$ for $24 \mathrm{~h}$. After washing the cells twice with PBS (Phosphate Buffered Saline), they were fixed in $4 \%$ paraformaldehyde at $25^{\circ} \mathrm{C}$ for $20 \mathrm{~min}$. The cells were stained with a rabbit polyclonal antibody specific for Bax (sc-493, $100 \mu \mathrm{g} / \mathrm{mL}$, Santa Cruz Biotech. Inc., CA, USA, dilution 1:1000) and active/cleaved caspase-3 (NB10056113, $250 \mu \mathrm{L}$, Novus Biologicals, Abingdon, UK, dilution 1:1000). After incubation, the cells were washed and treated with an appropriate secondary antibody, goat anti-rabbit IgG FITC (ab6717-1, $1 \mathrm{mg} / \mathrm{mL}$, Abcam, Cambridge, UK, dilution 1:2000). The sections were mounted with ProLong Gold antifade reagent with (4',6-diamidino-2-phenylindole) DAPI (Invitrogen) and analyzed at $\times 200$ magnification using a fluorescent microscope (Olympus BX 51).

\subsection{RNA Extraction and Real-Time $q R T-P C R$}

After $24 \mathrm{~h}$ treatment with IBS and MBS at a concentration of $2 \mu \mathrm{g} / \mathrm{mL}$, RNA was isolated from BCL1 and JVM-13 cells with TRIzol (Invitrogen, Carlsbad, CA, USA). Reverse transcription was performed on isolated RNA with a High-Capacity cDNA Reverse Transcription Kit (Applied Biosystems, Foster City, CA, USA). qRT-PCR was performed using Power SYBR MasterMix (Applied Biosystems) and mRNA-specific primers (Table 1). qPCR reactions were initiated with a $10 \mathrm{~min}$ incubation time at $95^{\circ} \mathrm{C}$ followed by 40 cycles of $95^{\circ} \mathrm{C}$ for $15 \mathrm{~s}$ and $60^{\circ} \mathrm{C}$ for $60 \mathrm{~s}$ in a Mastercycler ep realplex (Eppendorf, Hamburg, Ger- 
many). Relative expression of genes was calculated according to the formula $2^{-(\mathrm{Ct}-\mathrm{Ctactin})}$, where $C_{t}$ is the cycle threshold of the gene of interest and $C_{\text {tactin }}$ is the cycle threshold value of the housekeeping gene ( $\beta$-actin).

Table 1. Primers used for real-time qRT-PCR.

\begin{tabular}{|c|c|}
\hline Target & Sense and Antisense \\
\hline Mouse Bax & $\begin{array}{l}\text { 5'-ACACCTGAGCTGACCTTG-3' } \\
\text { 5'-AGCCCATGATGGTTCTGATC-3' }\end{array}$ \\
\hline Mouse caspase-3 & $\begin{array}{c}\text { 5'-AAATTCAAGGGACGGGTCAT-3' } \\
\text { 5'-ATTGACACAATACACGGGATCTGT-3' }\end{array}$ \\
\hline Mouse cyclin D3 & $\begin{array}{l}\text { 5' - CCGTGATTGCGCACGACTTC-3' } \\
5^{\prime} \text {-TCTGTGGGAGTGCTGGTCTG-3' }\end{array}$ \\
\hline Mouse Nanog & $\begin{array}{l}\text { 5'-AAGCAGAAGATGCGGACTGT-3' } \\
\text { 5'-GTGCTGAGCCCTTCTGAATC-3' }\end{array}$ \\
\hline Mouse Oct4 & $\begin{array}{l}\text { 5'-CAAGGCAAGGGAGGTAGACA-3' } \\
5^{\prime} \text {-ATGAGTGACAGACAGGCCAG-3' }\end{array}$ \\
\hline Mouse c-Myc & $\begin{array}{l}\text { 5'-CGGACACACAACGTCTTGGAA-3' } \\
\text { 5'-AGGATGTAGGCGGTGGCTTTT-3' }\end{array}$ \\
\hline Mouse $\beta$-actin & $\begin{array}{l}\text { 5'-AGCTGCGTTTTACACCCTTT-3' } \\
\text { 5'-AAGCCATGCCAATGTTGTCT -3' }\end{array}$ \\
\hline Human Bax & $\begin{array}{l}\text { 5'-ATGGACGGGTCCGGGGAGCA-3' } \\
\text { 5'-CCCAGTTGAAGTTGCCGTCA3-3' }\end{array}$ \\
\hline Human Bcl-2 & $\begin{array}{l}\text { 5'-CTTTGAGTTCGGTGGGGTCA-3', } \\
\text { 5'-GGGCCGTACAGTTCCACAAA-3' }\end{array}$ \\
\hline Human cMyc & $\begin{array}{l}\text { 5'-AAAGGCCCCCAAGGTAGTTA-3' } \\
5^{\prime} \text {-GCACAAGAGTTCCGTAGCTG-3' }\end{array}$ \\
\hline Human Nanog & $\begin{array}{l}\text { 5'-ACATGCAACCTGAAGACGTGTG-3' } \\
5^{\prime} \text {-CATGGAAACCAGAACACGTGG-3' }\end{array}$ \\
\hline Human Sox 2 & $\begin{array}{l}\text { 5'-GAGCTTTGCAGGAAGTTTGC-3' } \\
5^{\prime} \text {-GCAAGAAGCCTCTCCTTGAA-3' }\end{array}$ \\
\hline Human Oct4 & $\begin{array}{l}\text { 5'-ACATCAAAGCTCTGCAGAAAGAACT-3' } \\
5^{\prime} \text {-СTGAATACCTTCCCAAATAGAACCC-3' }\end{array}$ \\
\hline Human $\beta$-actin & $\begin{array}{l}\text { 5'-CACCATTGGCAATGAGCGGTTC-3' } \\
\text { 5'-AGGTCTTTGCGGATGTCCACGT-3' }\end{array}$ \\
\hline
\end{tabular}

\subsection{In Vivo Testing of Antitumor Activity}

Male BALB/c mice, aged 8-10 weeks old, were used for the experiments. All animals received humane care, and all experiments were approved by and conducted in accordance with the guidelines of the Animal Ethics Committee of the Faculty of Medicine, Kragujevac, Serbia. Mouse models of leukemia were conducted by intravenous injection of $1 \times 10^{6} \mathrm{BCL} 1$ cells into the tail vein. Twenty days after BCL1-cell inoculation, peripheral blood was tested by flow cytometry and mice with an increase in $\mathrm{CD}^{+} \mathrm{CD} 19^{+}$cells were randomly divided into six groups: (1) IBS, $2 \mathrm{mg} / \mathrm{kg}$; (2) IBS, $4 \mathrm{mg} / \mathrm{kg}$; (3) MBS $2 \mathrm{mg} / \mathrm{kg}$; (4) MBS $4 \mathrm{mg} / \mathrm{kg}$; (5) cyclophosphamide once weekly for 2 consecutive weeks at a dose of $100 \mathrm{mg} / \mathrm{kg}$ (maximal tolerable dose for BALB/c mice [14]); and (6) saline. The treatment with shikonins (intraperitoneal) lasted for two weeks and each mouse received six doses in total.

All mice were sacrificed two days after the last dose of shikonin derivatives. Mononuclear cells from blood and spleens incubated with anti-CD5 and anti-CD19 antibodies were analyzed by flow cytometry, and the data were analyzed using FlowJo (Tree Star). Serum levels of alanine amino transaminase (ALT), aspartate aminotransferase (AST), urea, and creatinine were measured by a standard photometric method using the Olympus AU 400 
automated biochemistry analyzer (Olympus Diagnostica GMBH, Hamburg, Germany) and Olympus AU reagents, according to the manufacturer's instructions.

\subsection{Statistical Analysis}

The data are presented as means \pm SDs. Statistical significance was determined by an independent sample Student $t$-test and ANOVA, and, where appropriate, a Mann-Whitney $U$-test or a Kruskal-Wallis test. Statistical significance was assumed at $p<0.05$. Statistical analyses were performed using SPSS 13.0.

\section{Results}

\subsection{Shikonin Derivates Significantly Reduce the Viability of BCL1 and JVM-13 Cells}

BCL1 and JVM-13 cell viability after treatment with growing concentrations of five different derivatives of shikonin, IBS, MBS, acetylshikonin, $\beta$-hydroxyisovalerylshikonin, and deoxyshikonin, for 24 and $48 \mathrm{~h}$ was analyzed by MTT assay and IC50 values were calculated. The obtained data did not show reduced viability of BCL1 and JVM-13 cells treated with $\beta$-hydroxyisovalerylshikonin and deoxyshikonin (Table 2). IC50 values for acetylshikonin after $24 \mathrm{~h}$ and $48 \mathrm{~h}$ of exposure indicated good cytotoxicity toward BCL1 and JVM-13 cells (Table 2). However, IBS and MBS reduced the viability of BCL1 and JVM-13 cells up to $50 \%$ in extremely low concentrations (Table 1 ). The cytotoxic effect of these derivatives was not time-dependent, and IC50 values after 24 and $48 \mathrm{~h}$ of exposure were nearly the same.

Table 2. The IC50 values of shikonins determined by MTT assay on BCL1 cell line.

\begin{tabular}{ccc}
\hline \multirow{2}{*}{ Compound } & \multicolumn{2}{c}{ IC $_{\mathbf{5 0}} \pm \mathbf{S D}(\boldsymbol{\mu g} / \mathbf{m L})$} \\
\cline { 2 - 3 } & $\mathbf{2 4 ~ \mathbf { ~ }}$ & $\mathbf{4 8 ~ h}$ \\
\hline Isobutyrylshikonin (IBS) & $0.86 \pm 0.16$ & $0.95 \pm 0.15$ \\
\hline$\alpha$-methylbutyrylshikonin (MBS) & $1.07 \pm 0.19$ & $1.02 \pm 0.20$ \\
\hline Acetylshikonin & $3.82 \pm 0.20$ & $3.88 \pm 0.20$ \\
\hline$\beta$-hydroxyisovalerylshikonin & $\geq 100$ & $\geq 100$ \\
\hline Deoxyshikonin & $\geq 100$ &
\end{tabular}

As shown in Figure 1, IBS and MBS decreased the viability of BCL1 and JVM-13 cells in a dose-dependent manner. From a concentration of $3 \mu \mathrm{g} / \mathrm{mL}$, both IBS and MBS reduced the viability of BCL1 cells to 100\% (Figure 1a). A similar effect was obtained on the JVM-13 cell line at a concentration of $10 \mu \mathrm{g} / \mathrm{mL}$ and higher for both shikonin derivatives (Figure 1b).

a

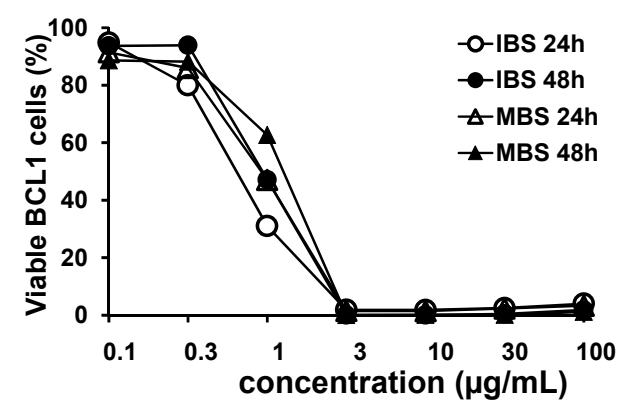

b

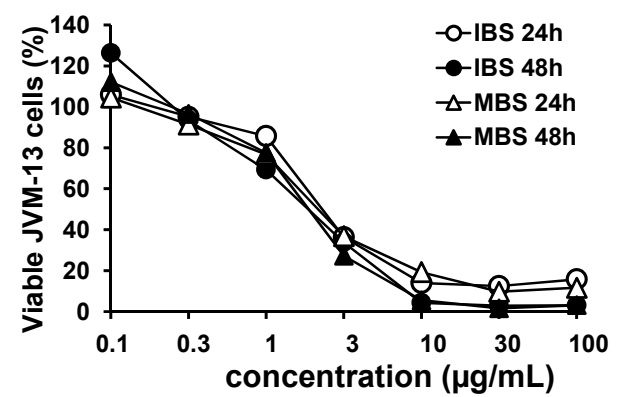

Figure 1. Dose- and time-dependent cytotoxicity of isobutyrylshikonin (IBS) and $\alpha$-methylbutyrylshikonin (MBS) on the BCL1 cell line. Graphs of (a) BCL1 and (b) JVM-13 cells' survival after 24 and $48 \mathrm{~h}$ growth in the presence of IBS and MBS determined by MTT assay. All data are presented as mean values from three independent experiments performed in triplicate. 


\subsection{IBS and MBS Induce Apoptosis of BCL1 and JVM-13 Cells}

In order to further investigate the antitumor potential of shikonin derivatives with the strongest potential to reduce the viability of BCL1 and JVM-13 cells, flow cytometric analysis of cells stained with Annexin V and PI after exposure to IBS and MBS for $24 \mathrm{~h}$ was done. As illustrated in Figure 2, IBS- and MBS-induced apoptosis and the majority of BCL1 and JVM-13 cells (Figure 2a) were in or occurred during late apoptosis. The percentage of late apoptotic cells was significantly higher $(p<0.005)$ after treatment with IBS and MBS at the $2 \mu \mathrm{g} / \mathrm{mL}$ concentration compared to untreated cells in both BCL1 (Figure 2a,b) and JVM-13 (Figure 2a) cell lines. Additionally, the percentage of late-apoptotic cells of both cell lines treated with lower concentrations of IBS and MBS was significantly lower in comparison with the percentage of cells treated with higher concentrations of tested derivatives of shikonin, showing that the pro-apoptotic effect of the substances is dose-dependent (Figure 2a). Treatment with IBS and MBS increased the percentage of early apoptotic cells as well, but percentages were lower compared to late apoptotic cells in both BCL1 and JVM-13 (Figure 2a) cell lines. Quantitative analysis of Bcl-2 and Bax and Mcl-1 and Noxa molecules in JVM-13 cells (Figure 2b) strongly indicated apoptotic death of JVM-13 cells after treatment with MBS and IBS. Treatment of JVM-13 cells with IBS and MBS at a concentration of $2 \mu \mathrm{g} / \mathrm{mL}$ significantly attenuated the percentage of Mcl-1-expressing cells and significantly enhanced the percentage of cells that expressed the pro-apoptotic molecule Noxa, even at a lower concentration of $1 \mu \mathrm{g} / \mathrm{mL}$ (Figure 2c). Analysis of Bax and Bcl-2 expression at mRNA levels also showed significant attenuation of Bcl-2 and enhancement of Bax mRNA levels after treatment of JVM-13 cells with IBS and MBS (Figure 2d). Similarly, tested shikonins at a concentration of $2 \mu \mathrm{g} / \mathrm{mL}$ significantly attenuated the percentage of Mcl-1 expressing BCL1 cells and enhanced the percentage of Noxa positive BCL1 cells (Figure 2e). mRNA levels of Bax were significantly higher in BCL1 cells treated with MBS and IBS (Figure 2c), while the mRNA levels of cleaved caspase-3 were also higher in treated cells but did not reach statistical significance (Figure 2f). In accordance with this finding, the expression of both pro-apoptotic molecules, Bax and cleaved caspase-3, at protein levels increased after MBS treatment (compared to untreated BCL1 cells) as evaluated by immunofluorescence staining (Figure 2g).
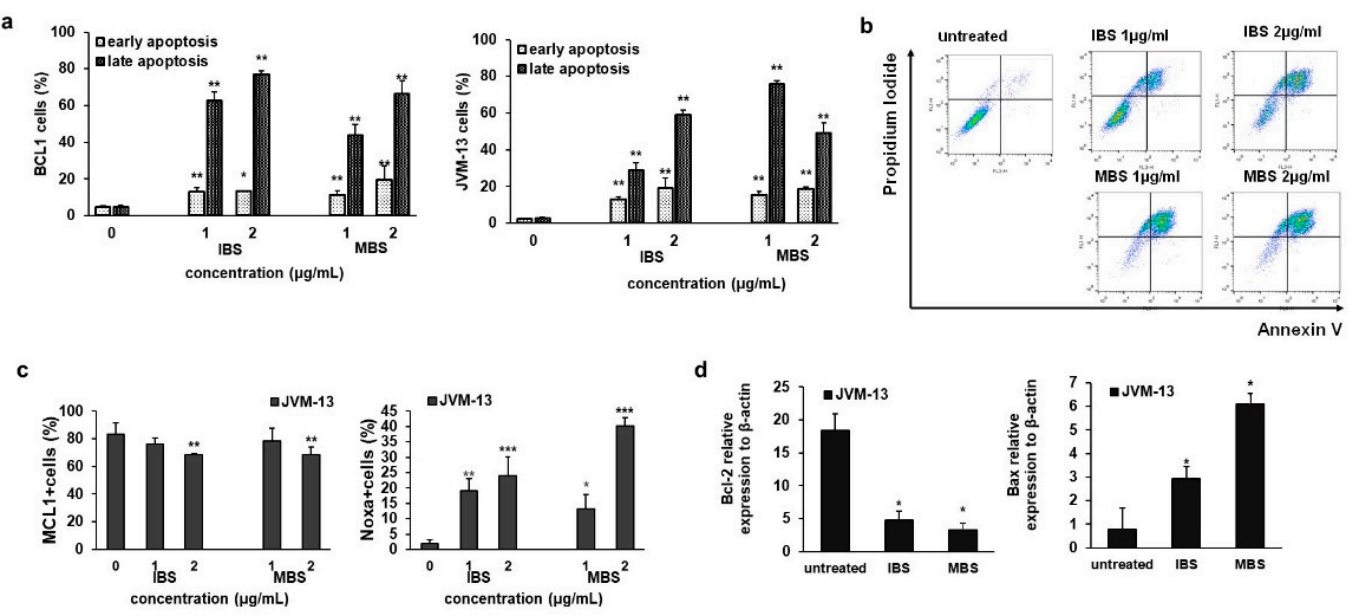

d
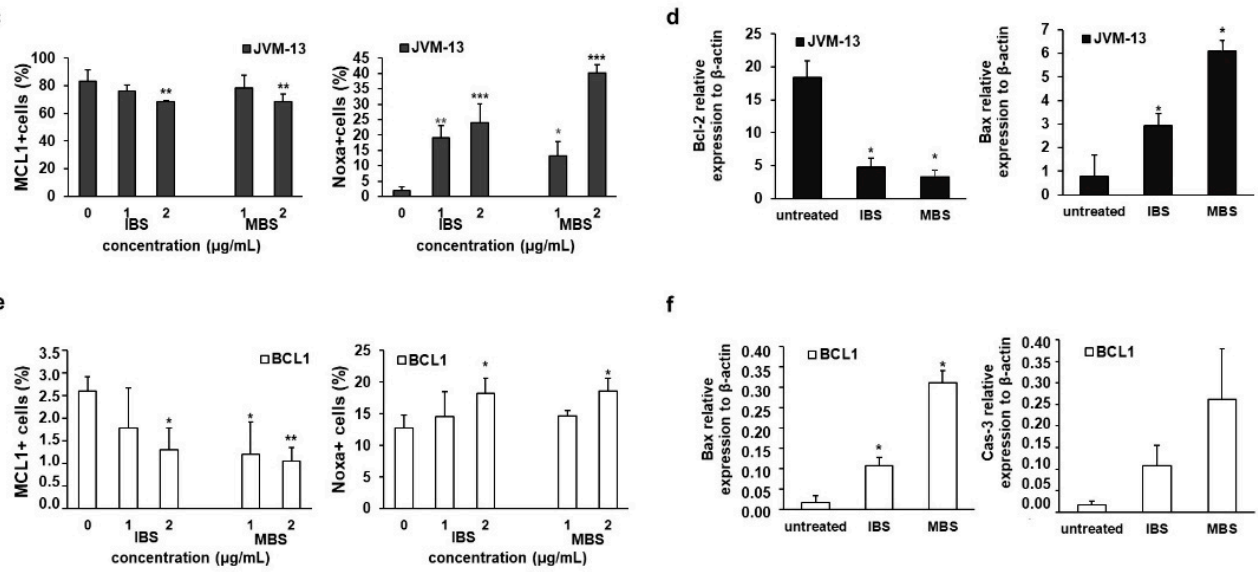

Figure 2. Cont. 
g

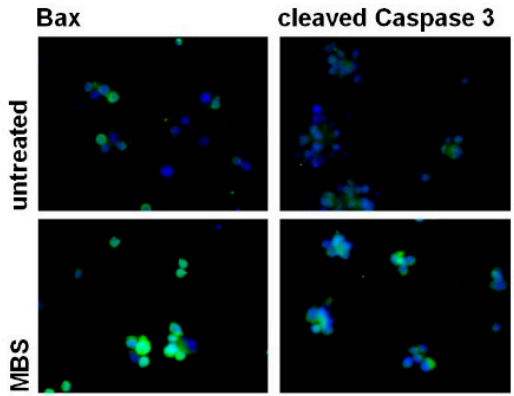

Figure 2. IBS and MBS induce apoptotic death of leukemia cells. Apoptosis of untreated and IBS- and MBS-treated BCL1 and JVM-13 cells for $24 \mathrm{~h}$ (a) evaluated by flow cytometry using Annexin V (FITC) and PI double staining. (b) Representative dot plots illustrate populations of viable (AnnV- PI-), early apoptotic (Ann V+ PI-), late apoptotic (AnnV+ PI+), and necrotic (AnnV-PI+) BCL1 cells treated with IBS or MBS. Percentage of Mcl-1 and Noxa positive (c) JVM-13 and (e) BCL1 cells evaluated by flow cytometry. mRNA expression of Bax and Bcl-2 in (d) JVM-13 and Bax and (f) caspase-3 expression in BCL1 cells treated by IBS and MBS quantified by qRT-PCR. (g) Immunofluorescence staining for Bax (green) and cleaved caspase-3 (green) together with DNA staining with DAPI (blue) in BCL1 cells incubated with MBS $(2 \mu \mathrm{g} / \mathrm{mL})$ for $24 \mathrm{~h}$, as well as in untreated cells (magnification $\times 200$ ). The data are presented as means + SDs of a three independent experiment. ${ }^{*} p<0.05,{ }^{* *} p<0.01$, *** $p<0.001$ indicate differences between treated and untreated cells.

\subsection{Derivatives of Shikonin Show Antiproliferative Effect against BCL1 Cells}

The anti-proliferative effects of testing molecules were evaluated by assessment of the Ki67 expression level in treated cells using flow cytometry. The percentage of Ki67 positive BCL1 and JVM-13 cells (Figure 3a) treated with IBS and MBS was significantly lower compared to untreated cells. Additionally, lower expressions of $\mathrm{Ki} 67$ were found in treated IBS and MBS compared to untreated BCL1 and JVM-13 cells (Figure 3b).

a
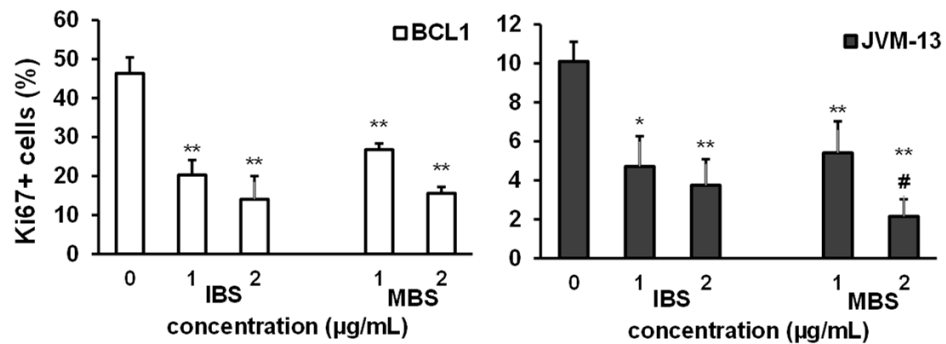

b

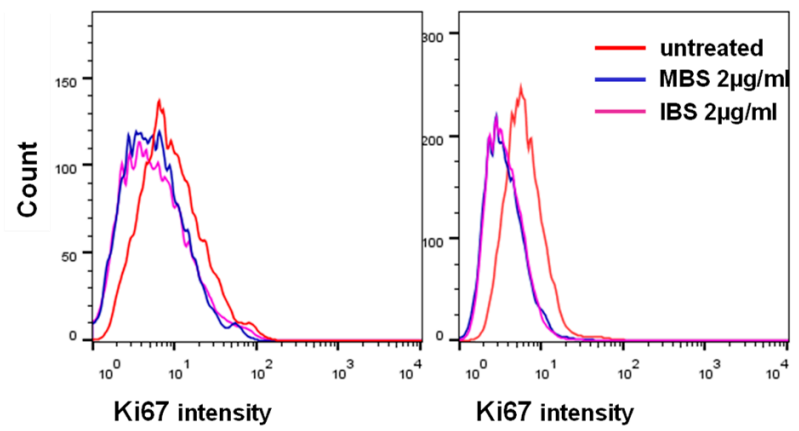

Figure 3. IBS and MBS attenuate the expression of Ki67 in BCL1 and JVM-13 cells. (a) Percentage of Ki-67 positive BCL1 and JVM-13 cells exposed to IBS and MBS (concentrations $=1$ and $2 \mu \mathrm{g} / \mathrm{mL}$ ) for $24 \mathrm{~h}$ determined by flow cytometry presented as the mean + SD from three independent experiments. Data were analyzed with Student's $t$-test: ${ }^{*} p<0.05 ;{ }^{* *} p<0.01$, $\# p<0.05$ (indicates differences between two doses of MBS). (b) Representative histograms of Ki67 expression (mean fluorescence intensity) in BCL1 and JVM-13 cells. 
Both shikonin derivatives, in accordance with reduced Ki67 expression (Figure 3a,b), significantly reduced the percentage of BCL1 cells in the S phase of the cell cycle (Figure 4a). Treatment with IBS significantly increased the percentage of BCL1 cells in the G2/M phase compared to untreated cells (Figure 4a). Furthermore, the percentage of BCL1 cells in the G0/G1 phase decreased after IBS treatment. On the other hand, MBS treatment significantly increased the percentage of BCL1 cells in the G0/G1 phase compared to untreated cells and decreased the percentage of these cells in the G2/M phase (Figure 4a). However, both tested derivatives of shikonin significantly increased the percentage of JVM-13 cells in the G0/G1 phase and decreased the percentage of these cells in the S and G2/M phases (Figure 4b). A significant reduction in the expression of cyclin D3 mRNA was detected in IBS- and MBS-treated BCL1 cells in comparison with untreated cells (Figure 4c). Additionally, a significant decrease in the percentage of cyclin-D3-expressing JVM-13 cells after treatment with IBS $(2 \mu \mathrm{g} / \mathrm{mL})$, and with both tested concentrations of MBS, was noticed (Figure $4 \mathrm{~d})$. The percentage of BCL1 cells expressing the inhibitor of cyclin D-CDK4 complex, p16, was significantly enhanced after treatment with IBS and MBS compared to untreated BCL1 cells (Figure 4e). No significant change in the expression of p21 and p27 BCL1 cells treated with IBS was noticed (Figure 4e). However, the treatment of BCL1 cells with MBS significantly increased the percentage of p21- and p27-expressing cells compared to untreated BCL1 cells (Figure 4e).
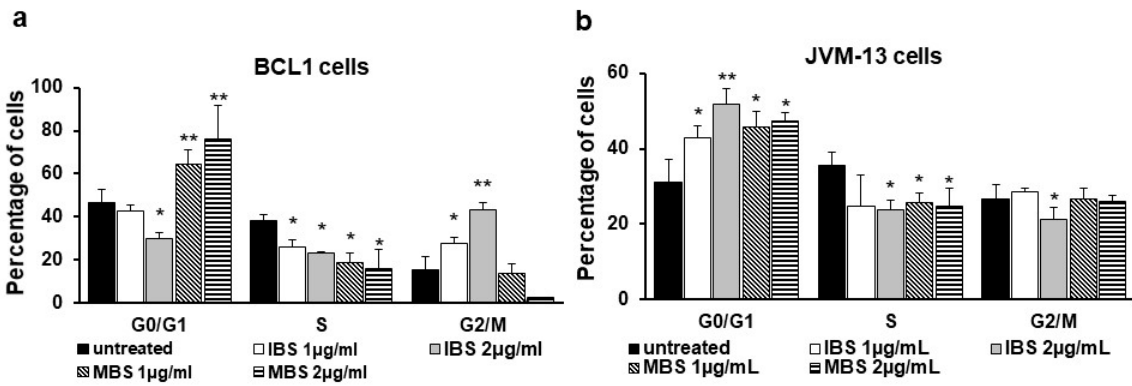

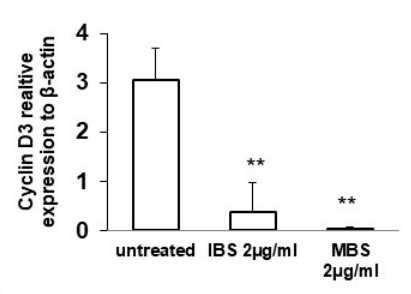

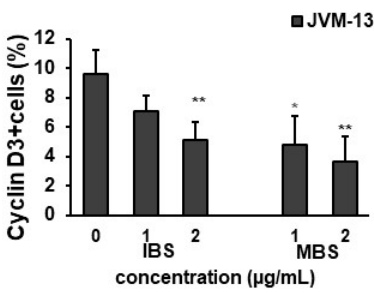
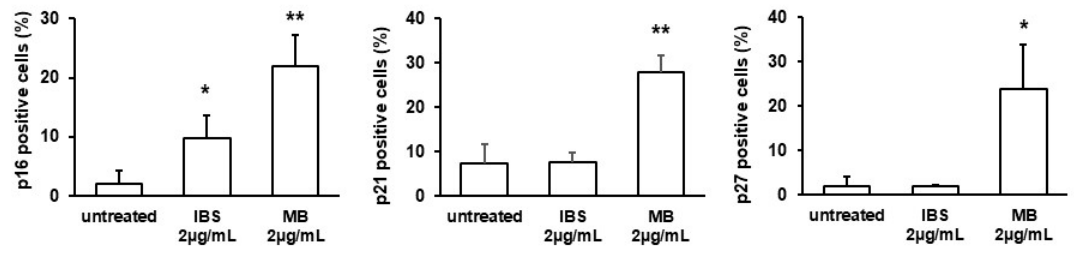

Figure 4. IBS and MBS induce cell cycle disturbances in JVM-13 and BCL1 cells. Distribution of (a) BCL1 and (b) JVM-13 cells in different phases of the cell cycle after treatment with IBS and MBS (concentrations $=1 \mu \mathrm{g} / \mathrm{mL}$ and $2 \mu \mathrm{g} / \mathrm{mL}$ ) was determined by flow cytometry after staining with Vybrant ${ }^{\circledR}$ DyeCycle ${ }^{\mathrm{TM}}$ Ruby stain. Results are expressed as the percentage of cells in different phases of the cell cycle. (c) mRNA expression of cyclin D3 quantified by RT-PCR in BCL1 cells after treatment with IBS and MBS $(2 \mu \mathrm{g} / \mathrm{mL})$ for $24 \mathrm{~h}$. (d) Percentage of JVM-13 cells expressing cyclin D3 after treatment with two different concentrations of IBS and MBS $(1 \mu \mathrm{g} / \mathrm{mL}$ and $2 \mu \mathrm{g} / \mathrm{mL})$ for $24 \mathrm{~h}$ determined by flow cytometry. (e) Percentage of p16-, p21-, and p27-positive BCL1 cells analyzed by flow cytometry after $24 \mathrm{~h}$ treatment with IBS and MBS. Data are presented as the mean \pm SD. ${ }^{*} p<0.05,{ }^{* *} p<0.01$ indicates a significant difference from untreated cells. 


\subsection{Shikonin Derivatives Inhibit Expression of $\mathrm{pSTAT3}$ and STAT3 Regulated Genes}

Since it has been shown that inhibition of STAT3 signaling leads to CLL cell death [15] and that the antitumor effects of shikonins are mediated by STAT3 inhibition [16,17], the expression of pSTAT3 in IBS- and MBS-treated BCL1 and JVM-13 cells was analyzed by flow cytometry. Treatment with IBS and MBS significantly reduced the percentage of pSTAT3-expressing BCL1 and JVM-13 cells compared to untreated cells (Figure 5a). This was accompanied by a significantly lower expression of c-Myc, Nanog, and Oct4 mRNA in BCL1 cells and a lower expression of c-Myc, Nanog, Sox2, and Oct4 mRNA in JVM-13 cells (Figure $5 b$ ). To further explore the role of shikonin-induced STAT3 inhibition in tumor cell death, the cytotoxic activity of combination of IBS and MBS with the single agent inhibitor of Jak2 (AG490), a molecule that phosphorylates STAT3, was analyzed by MTT assay. As shown in Figure 5c, AG490 alone does not reduce the viability of BCL1 cells after $24 \mathrm{~h}$ of exposure. However, simultaneous treatment with AG490 and IBS or MBS induces a significantly higher reduction in BCL1 cell viability in comparison with the single treatment (Figure 5c).
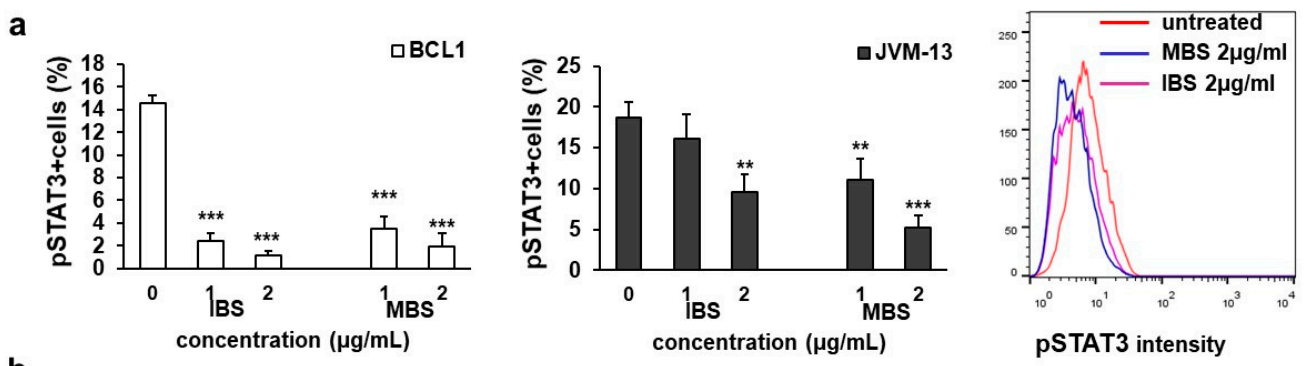

b
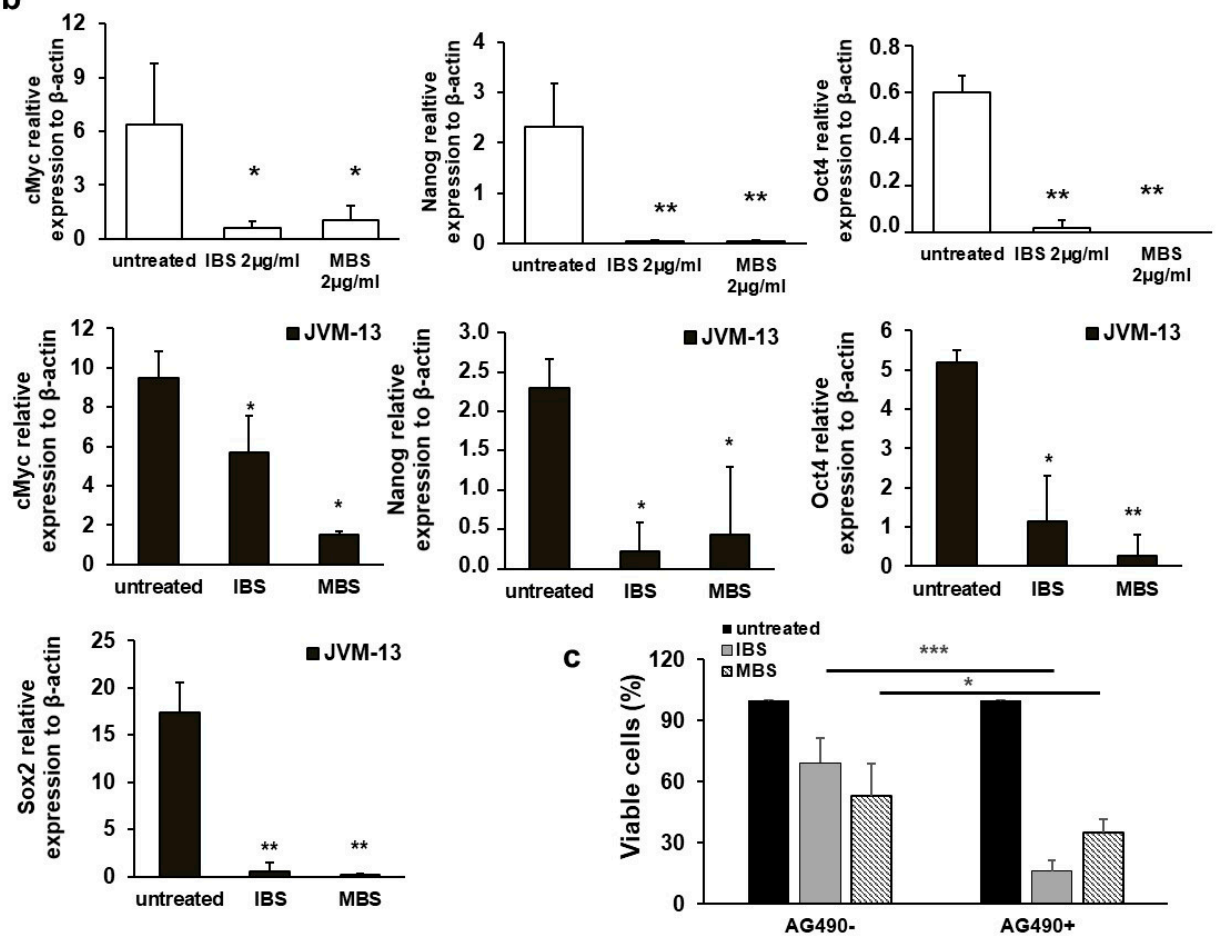

Figure 5. Treatment with IBS and MBS attenuates the expression of PSTAT3- and STAT3-regulated genes in BCL1 and JVM-13 cells. (a) Percentages of PSTAT3 positive BCL1 and JVM-13 cells determined by flow cytometry $24 \mathrm{~h}$ after treatment with IBS and MBS and representative histograms of pSTAT3 expression in JVM-13 cells. (b) mRNA expression of c-Myc, Nanog, and Oct4 in BCL1 cells and c-Myc, Nanog, Sox2 and Oct4 in JVM-13 cells treated with IBS and MBS quantified by RT-PCR. (c) BCL1 cells' survival after $24 \mathrm{~h}$ growth in the presence of IBS and MBS, with or without the addition of Jak2 inhibitor AG490 (tyrphostin), determined by MTT assay. Data are presented as the mean \pm SD. ${ }^{*} p<0.05,{ }^{* *} p<0.01,{ }^{* * *} p<0.001$. 


\subsection{Shikonin Derivatives Reduced BCL1 Cell Growth In Vivo}

According to results obtained by the MTT test, we investigated the potential of IBS and MBS to reduce the growth of leukemia cells in BALB/c mice intravenously injected with BCL1 cells. Cyclophosphamide was used as a control substance. Treatment with two different doses of IBS and MBS $(2 \mathrm{mg} / \mathrm{kg}$ and $4 \mathrm{mg} / \mathrm{kg}$ ) significantly reduced the percentage of CD5+CD19+ cells in the peripheral blood and spleen of BCL1-injected BALB/c mice (Figure 6a,b). A significantly higher dose of IBS and MBS $(4 \mathrm{mg} / \mathrm{kg}$ ) led to a decrease in the percentage of leukemic cells in the spleen similar to the decrease induced by cyclophosphamide treatment (Figure 6b). Importantly, IBS and MBS treatment did not significantly change the serum level of ALT, AST, urea, and creatinine (Figure 6c).

b
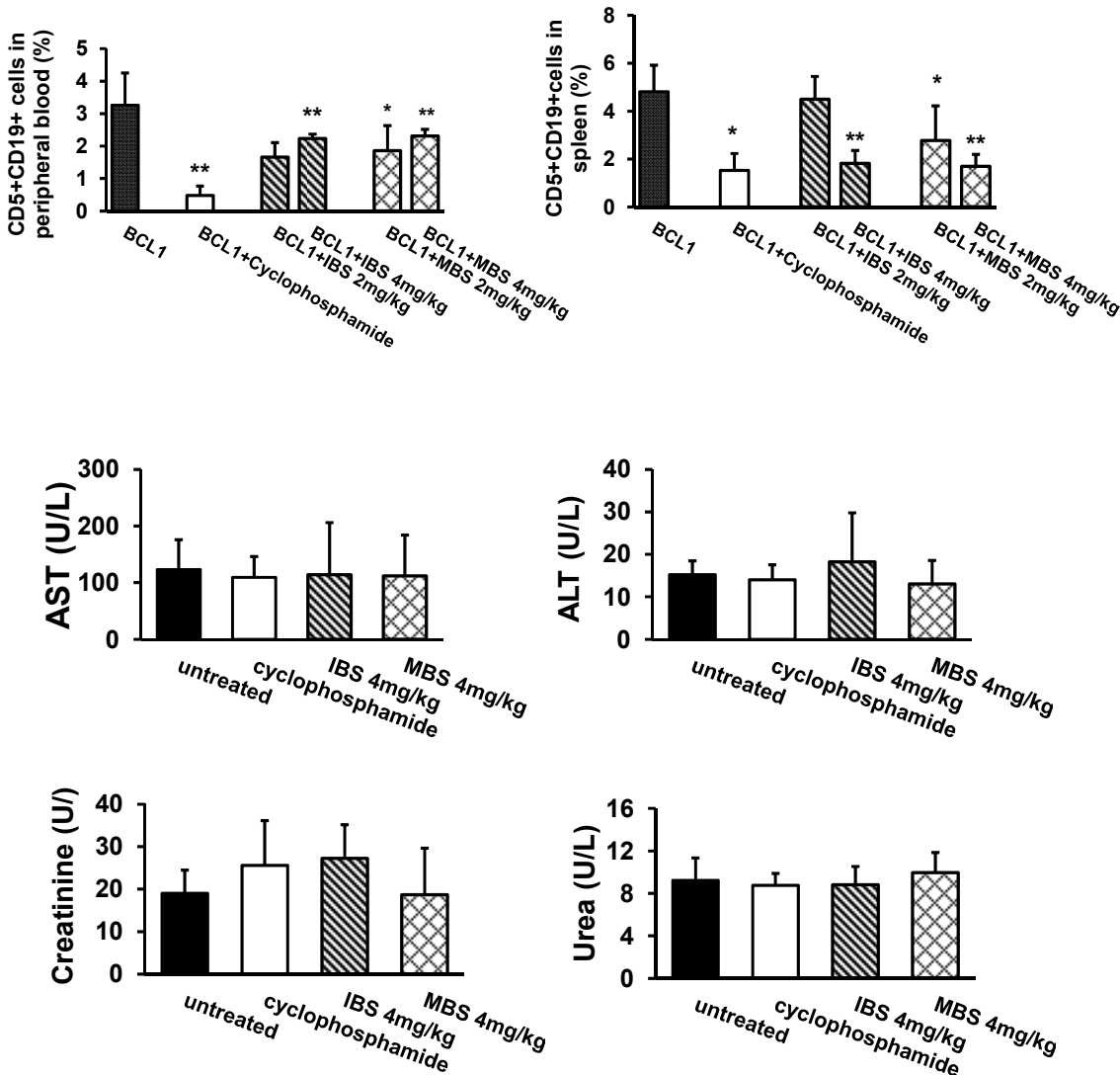

Figure 6. Treatment with IBS and MBS inhibits BCL1 leukemia growth in vivo. Mononuclear cells from (a) peripheral blood and (b) spleens of untreated and IBS- and MBS-treated mice 20 days after intravenous BCL1 cell injection $\left(1 \times 10^{6}\right)$. The percentage of CD5+CD19+ BCL1 cells is presented as the mean $\pm \mathrm{SD}$. ${ }^{*} p<0.05,{ }^{* *} p<0.01$. (c) AST, ALT, urea, and creatinin levels were determined in the serum 90 days after the BCL1 injection in untreated and IBS- and MBS-treated mice, presented as the mean $\pm \mathrm{SD}$ (eight animals per group).

\section{Discussion}

CLL is a slowly progressive but still incurable disease due to the presence of apoptosisresistant lymphocytes that proliferate in bone marrow and lymph nodes [18]. Therefore, exploring new treatment options capable to induce apoptosis in CLL cells is necessary. In this study, we provide the first evidence that isobutyrylshikonin and $\alpha$-methylbutyrylshikonin, two naphthoquinones extracted from the roots of Onosma visianii, induce strong apoptotic, antiproliferative, and STAT3-dependent cytotoxic effects in mouse CLL cells, BCL1, and human B-PLL cells, JVM-13, with significant in vivo antitumor effects.

Shikonin is a well-known antitumor substance that induces apoptosis, inhibits proliferation of cancer cells, and inhibits angiogenesis. The antitumor effects of shikonin have 
been described in various tumors including leukemia [19]. Previous reports indicate that root extracts and several shikonin derivatives isolated from the endemic plant of the Balkan peninsula, Onosma visianii, exert antitumor effects in vitro $[2,20]$ but also bind human albumin well [21], suggesting that they could be effectively transported by serum albumin and could have antitumor effects in vivo. In this study, we confirmed that two shikonin derivatives, IBS and MBS, significantly reduced viability, suppressed proliferation, and induced apoptotic death in BCL1 and JVM-13 cells in a dose-dependent manner (Figures 1-3). This finding is in line with findings from previous testing of naphthoquinones isolated from Onosma visianii, which revealed that IBS significantly reduced the viability of human colorectal cancer cells [2]. Here, we have also shown that the therapeutic application of IBS and MBS in mice with BCL1 leukemia induced marked antitumor action as evaluated by a reduced number of BCL1 cells counted in peripheral blood (Figure 6a) and spleen (Figure 6b). Additionally, an important observation is that both IBS and MBS induced a decrease in tumor cells in the spleens almost as effective as cyclophosphamide (Figure $6 \mathrm{~b}$ ).

In line with previous findings that shikonin induce apoptosis in tumor cells [22,23], we found that IBS and MBS induce apoptotic death in BCL1 and JVM-13 treated cells (Figure 2). The majority of BCL1 and JVM-13 cells treated with both doses of IBS and MBS were late apoptotic (Figure 2a), suggesting very prompt pro-apoptotic effects. Furthermore, the high expression of molecules that play an important role in the apoptotic cell death, Bax and cleaved caspase-3 [24], was observed in MBS-treated BCL1 cells (as evaluated by immunofluorescence) (Figure 2g). In line with these findings, treatment with IBS and MBS upregulate mRNA levels of Bax and caspase-3 (Figure 2f). A decrease of anti-apoptotic Mcl1 and an increase of pro-apoptotic Noxa was also observed in both cell lines (Figure 2c,e), proteins whose relative ratio controls apoptosis [25]. Our results suggest that IBS and MBS induce apoptosis in BCL1 and JVM-13 cells and are in accordance to previous findings that shikonin induces a decrease in Bcl-2 and an increase in Bax expression, enhances the activities of caspase-3, and induces apoptotic cell death [26,27].

A recent study showed that shikonin could suppress cell proliferation via arresting the cell cycle at the G0/G1 or the G2/M phase [2]. We have shown that both derivatives increased the percentage of JVM-13 cells in the G0/G1 phase (Figure 4b), while the percentage of BCL1 cells in the G0/G1 phase was increased after MBS treatment (Figure 4a). Cyclin D3 binds to CDK4 and CDK6 and plays a role as the initial activator of the G1 phase [28-31]. In line with this, MBS treatment induced a decrease in the mRNA level of cyclin D3 in BCL1 cells (Figure 4c) and the percentage of cyclin D3 expressing JVM-13 (Figure 4d) but significantly enhanced the expression of the protein level of the inhibitor of cyclin D-CDK4/CDK6 complex, p16 [28], the universal cyclin-CDK inhibitor, p21 [29], and the inhibitor of cyclin E-CDK2, cyclin A-CDK2, and cyclin D-CDK4 complexes, p27 [30], in BCL1 cells (Figure 4e). IBS and MBS significantly decreased the percentage of BCL1 and JVM-13 cells expressing Ki67 (Figure 3a), attenuated the expression of this molecule in both cell types (Figure 3b), and significantly decreased the percentage of these cells in the $S$ phase of the cell cycle (Figure $4 a, b)$. Given these results, it can be assumed that MBS inhibits BCL1 and JVM-13 cells' proliferation by arresting them in the G0/G1 phase of the cell cycle. A similar effect of IBS was also observed in JVM-13 cells. However, IBS-treated BCL1 cells were arrested in the G2/M phase, had a lower expression of cyclin D3, and a higher expression of p16 in comparison with untreated cells (Figure 4). Previously, it has been shown that low doses of UV radiation induce G2 phase cell cycle arrest accompanied with increased expression of p16 that binds to Cdk4 and Cdk6 complexes and inhibits a cyclin D3-CDK4 complex normally activated in late S/early G2 phase [32]. Our finding of lower expression of cyclin D3, higher expression of p16, and unchanged expression of p21 and p27 in BCL1 cells (Figure 4) are in line with this finding. The arrest of BCL1 cells in different phases of the cell cycle induced by different derivatives of shikonin obtained in this study may explain the different effects of various root extracts (acetone or chloroform) on cell cycle progression previously reported, since differently obtained extracts could contain different percentages of active compounds [2]. 
Results from in vitro studies indicate that STAT3 inhibition increases the Bax/Bcl-2 ratio leading to apoptosis of tumor cells [6]. Additionally, STAT3 plays a key role in the G1 to $S$ phase cell-cycle transition by the upregulation of cyclin D1, D2, D3 and the concomitant downregulation of p21 and p27 [15]. The present study revealed that MBS and IBS treatment significantly decreased the percentage of BCL1 and JVM-13 cells expressing pSTAT3 (Figure 5a). Decreased expression of pSTAT3 accompanied with increased expression of Bax, increased apoptosis of BCL1 and JVM-13 cells (Figure 2), decreased expression of cyclin D3, and increased expression of inhibitors of CDKs (Figure 4) is in agreement with previous reports $[6,33]$.

It has recently been shown that JAK2 inhibitor, AG490, causes the dephosphorylation of STAT3 and enhances cytotoxic activity of conventional chemotherapeutics in leukemia cells [15]. To further confirm the link between decrease of pSTAT3 and enhanced death of BCL1 cells, these cells were co-treated with AG490 and MBS or IBS. As shown in Figure 5c, a significant decrease in viable BCL1 cells co-treated with AG490 and MBS or IBS in comparison with IBS or MBS treatment alone was noticed, supporting the hypothesis that IBS and MBS cytotoxic activity toward BCL1 cells is at least partially mediated by regulation of the activity of STAT3 signaling.

Aberrant expression of Nanog, Oct4, and c-Myc, downstream proteins of the STAT3 signaling pathway, was found in several cancers and is accompanied with cancer stemness [34]. In this study, we have shown that MBS and IBS treatment significantly decreased mRNA expression of Nanog, Oct4 and c-Myc in BCL1 cells and Nanog, Oct4, Sox2 and c-Myc in JVM-13 cells compared to untreated cells (Figure 5b). The correlation of the decreased percentage of leukemic cells containing Y705 phospho-STAT3 (Figure 5a) and the decreased expression of Nanog, Oct4, Sox2 and c-Myc (Figure 5b) after treatment with MBS or IBS mRNA is in line with a previous report that found inhibited phosphorylation of Stat 3 decreased the expression of Oct- 4 and c-Myc in breast cancer cells [16].

\section{Conclusions}

In conclusion, we reported that IBS and MBS exhibit a considerable antitumor effect in CLL and B-PLL cells. This effect was achieved by the reduction of STAT3 phosphorylation and signaling and the consecutive triggering of apoptotic cell death, inhibition of cell proliferation, and attenuation of cancer stemness. These results highlight the necessity of further testing of shikonin derivatives as possible new anticancer agents or auxiliary drugs.

Author Contributions: Conceptualization and design, Z.T., M.M., N.A., P.D. Experiment performance, Z.T., J.M., D.A., A.A., M.V., N.V. Data analysis, Z.T., J.M., A.A., M.M., D.A., N.V., N.A., P.D. Writing, M.M., Z.T., N.A., P.D. All authors have read and agreed to the published version of the manuscript.

Funding: This work was funded by grants from the Ministry of Education, Science and Technological Development of the Republic of Serbia (grant no. ON175069), the Serbian bilateral project with PR China (06/2018), and The Faculty of Medical Sciences, University of Kragujevac (JP 17/19).

Institutional Review Board Statement: All animal procedures were approved by the Ethical Committee of the Faculty of Medical Sciences, University of Kragujevac, Serbia (No 01-8686/8).

Data Availability Statement: Data described in the manuscript will be made available upon reasonable request from the corresponding author.

Conflicts of Interest: The authors declare no conflict of interest.

\section{References}

1. Andújar, I.; Ríos, J.L.; Giner, R.M.; Recio, M.C. Pharmacological properties of shikonin-A review of literature since 2002. Planta Med. 2013, 79, 1685-1697. [CrossRef]

2. Vukic, M.D.; Vukovic, N.L.; Djelic, G.T.; Popovic, S.L.J.; Zaric, M.M.; Baskic, D.D.; Krstic, G.B.; Tesevic, V.V.; Kacaniova, M.M. Antibacterial and cytotoxic activities of naphthoquinone pigments from Onosma visianii Clem. EXCLI J. 2017, 16, 73-88. 
3. Wiench, B.; Chen, Y.R.; Paulsen, M.; Hamm, R.; Schröder, S.; Yang, N.S.; Efferth, T. Integration of Different “-omics" Technologies Identifies Inhibition of the IGF1R-Akt-mTOR Signaling Cascade Involved in the Cytotoxic Effect of Shikonin against Leukemia Cells. Evid. Based Complementary Altern. Med. 2013, 2013, 818709. [CrossRef]

4. Johnston, P.A.; Grandis, J.R. STAT3 signaling: Anticancer strategies and challenges. Mol. Interv. 2011, 11, 18-26. [CrossRef] [PubMed]

5. Hazan-Halevy, I.; Harris, D.; Liu, Z.; Liu, J.; Li, P.; Chen, X.; Shanker, S.; Ferrajoli, A.; Keating, M.J.; Estrov, Z. STAT3 is constitutively phosphorylated on serine 727 residues, binds DNA, and activates transcription in CLL cells. Blood 2010, 115, 2852-2863. [CrossRef]

6. Maryam, A.; Mehmood, T.; Yan, Q.; Li, Y.; Khan, M.; Ma, T. Proscillaridin A Promotes Oxidative Stress and ER Stress, Inhibits STAT3 Activation, and Induces Apoptosis in A549 Lung Adenocarcinoma Cells. Oxid. Med. Cell Longev. 2018, $2018,3853409$. [CrossRef]

7. Amini, S.; Fathi, F.; Mobalegi, J.; Sofimajidpour, H.; Ghadimi, T. The expressions of stem cell markers: Oct4, Nanog, Sox2, nucleostemin, Bmi, Zfx, Tcl1, Tbx3, Dppa4, and Esrrb in bladder, colon, and prostate cancer, and certain cancer cell lines. Anat. Cell Biol. 2014, 47, 1-11. [CrossRef]

8. Noone, A.M.; Howlader, N.; Krapcho, M.; Miller, D.; Brest, A.; Yu, M.; Ruhl, J.; Tatalovich, Z.; Mariotto, A.; Lewis, D.R.; et al. (Eds.) SEER Cancer Statistics Review, 1975-2015; Based on November 2017 SEER Data Submission, Posted to the SEER Web Site; National Cancer Institute: Bethesda, MD, USA, April 2018.

9. Roberts, A.W.; Davids, M.S.; Pagel, J.M.; Kahl, B.S.; Puvvada, S.D.; Gerecitano, J.F.; Kipps, T.J.; Anderson, M.A.; Brown, J.R.; Gressick, L.; et al. Targeting BCL2 with venetoclax inrelapsed chronic lymphocytic leukemia. N. Engl. J. Med. 2016, 374, 311-322. [CrossRef] [PubMed]

10. Rozovski, U.; Harris, D.M.; Li, P.; Liu, Z.; Jain, P.; Veletic, I.; Ferrajoli, A.; Burger, J.; Thompson, P.; Jain, N.; et al. Activation of the B-cell receptor successively activates NF- KB and STAT3 in chronic lymphocytic leukemia cells. Int. J. Cancer 2017, 141, $2076-2081$. [CrossRef] [PubMed]

11. Campo, E.; Swerdlow, S.H.; Harris, N.L.; Pileri, S.; Stein, H.; Jaffe, E.S. The 2008 WHO classification of lymphoid neoplasms and beyond: Evolving concepts and practical applications. Blood 2011, 117, 5019-5032. [CrossRef]

12. Galton, D.A.; Goldman, J.M.; Wiltshaw, E.; Catovsky, D.; Henry, K.; Goldenberg, G.J. Prolymphocytic leukaemia. Br. J. Haematol. 1974, 27, 7-23. [CrossRef] [PubMed]

13. Dearden, C. How I treat prolymphocytic leukemia. Blood 2012, 120, 538-551. [CrossRef] [PubMed]

14. Molyneux, G.; Andrews, M.; Sones, W.; York, M.; Barnett, A.; Quirk, E.; Yeung, W.; Turton, J. Haemotoxicity of busulphan, doxorubicin, cisplatin and cyclophosphamide in the female BALB/c mouse using a brief regimen of drug administration. Cell Biol. Toxicol. 2011, 27, 13-40. [CrossRef] [PubMed]

15. Severin, F.; Frezzato, F.; Visentin, A.; Martini, V.; Trimarco, V.; Carraro, S.; Tibaldi, E.; Brunati, A.M.; Piazza, F.; Semenzato, G.; et al. In Chronic Lymphocytic Leukemia the JAK2/STAT3 Pathway Is Constitutively Activated and Its Inhibition Leads to CLL Cell Death Unaffected by the Protective Bone Marrow Microenvironment. Cancers 2019, 11, 1939. [CrossRef] [PubMed]

16. Cheng, C.C.; Shi, L.H.; Wang, X.J.; Wang, S.X.; Wan, X.Q.; Liu, S.R.; Wang, Y.F.; Lu, Z.; Wang, L.H.; Ding, Y. Stat3/Oct-4/c-Myc signal circuit for regulating stemness-mediated doxorubicin resistance of triple-negative breast cancer cells and inhibitory effects of WP1066. Int. J. Oncol. 2018, 53, 339-348. [CrossRef]

17. Thakur, R.; Trivedi, R.; Rastogi, N.; Singh, M.; Mishra, D.P. Inhibition of STAT3, FAK and Src mediated signaling reduces cancer stem cell load, tumorigenic potential and metastasis in breast cancer. Sci. Rep. 2015, 5, 10194. [CrossRef]

18. Messmer, B.T.; Messmer, D.; Allen, S.L.; Kolitz, J.E.; Kudalkar, P.; Cesar, D.; Murphy, E.J.; Koduru, P.; Ferrarini, M.; Zupo, S.; et al. In vivo measurements document the dynamic cellular kinetics of chronic lymphocytic leukemia B cells. J. Clin. Investig. 2005, 115, 755-764. [CrossRef]

19. Mao, X.; Yu, C.R.; Li, W.H.; Li, W. XInduction of apoptosis by shikonin through a ROS/JNK-mediated process in Bcr/Ablpositive chronic myelogenous leukemia (CML) cells. Cell Res. 2008, 18, 879-888. [CrossRef]

20. Vukic, M.D.; Vukovic, N.L.; Obradovic, A.D.; Popovic, S.L.; Zaric, M.M.; Djurdjevic, P.M.; Markovic, S.D.; Baskic, D.D. Naphthoquinone rich Onosma visianii Clem (Boraginaceae) root extracts induce apoptosis and cell cycle arrest in HCT-116 and MDA-MB-231 cancer cell lines. Nat. Prod. Res. 2018, 32, 2712-2716. [CrossRef]

21. Vukic, M.D.; Vukovic, N.L.; Obradovic, A.; Matic, M.; Djukic, M.; Avdovic, E. Redox status, DNA and HSA binding study of naturally occurring naphthoquinone derivatives. EXCLI J. 2020, 19, 48-70.

22. Chen, Y.; Wang, T.; Du, J.; Li, Y.; Wang, X.; Zhou, Y.; Yu, X.; Fan, W.; Zhu, Q.; Tong, X.; et al. The Critical Role of PTEN/PI3K/AKT Signaling Pathway in Shikonin-Induced Apoptosis and Proliferation Inhibition of Chronic Myeloid Leukemia. Cell Physiol. Biochem. 2018, 47, 981-993. [CrossRef]

23. Shan, Z.L.; Zhong, L.; Xiao, C.L.; Gan, L.G.; Xu, T.; Song, H.; Yang, R.; Li, L.; Liu, B.Z. Shikonin suppresses proliferation and induces apoptosis in human leukemia NB4 cells through modulation of MAPKs and c-Myc. Mol. Med. Rep. 2017, 16, 3055-3060. [CrossRef] [PubMed]

24. Henkels, K.M.; Turchi, J.J. Cisplatin-induced Apoptosis Proceeds by Caspase-3-dependent and -independent Pathways in Cisplatin-resistant and -sensitive Human Ovarian Cancer Cell Lines. Cancer Res. 1999, 59, 3077-3083. [PubMed]

25. Alves, N.L.; Derks, I.A.; Berk, E.; Spijker, R.; van Lier, R.A.; Eldering, E. The Noxa/Mcl-1 axis regulates susceptibility to apoptosis under glucose limitation in dividing T cells. Immunity 2006, 24, 703-716. [CrossRef] [PubMed] 
26. Gara, R.K.; Srivastava, V.K.; Duggal, S.; Bagga, J.K.; Bhatt, M.; Sanyal, S.; Mishra, D.P. Shikonin selectively induces apoptosis in human prostate cancer cells through the endoplasmic reticulum stress and mitochondrial apoptotic pathway. J. Biomed. Sci. 2015, 22, 26. [CrossRef]

27. Jia, L.; Zhu, Z.; Li, H.; Li, Y. Shikonin inhibits proliferation, migration, invasion and promotes apoptosis in NCI-N87 cells via inhibition of PI3K/AKT signal pathway. Artif. Cells Nanomed. Biotechnol. 2019, 47, 2662-2669. [CrossRef] [PubMed]

28. Deshpande, A.; Sicinski, P.; Hinds, P.W. Cyclins and cdks in development and cancer: A perspective. Oncogene 2005, 24, 2909-2915. [CrossRef]

29. Sherr, C.J.; Roberts, J.M. CDK inhibitors: Positive and negative regulators of G1-phase progression. Genes Dev. 1999, 13, 1501-1512. [CrossRef]

30. Xiong, Y.; Hannon, G.J.; Zhang, H.; Casso, D.; Kobayashi, R.; Beach, D. p21 is a universal inhibitor of cyclin kinases. Nature 1993, 366, 701-704. [CrossRef]

31. Zhu, Y.; Zhong, Y.; Long, X.; Zhu, Z.; Zhou, Y.; Ye, H.; Zeng, X.; Zheng, X. Deoxyshikonin isolated from Arnebia euchroma inhibits colorectal cancer by down-regulating the PI3K/Akt/mTOR pathway. Pharm. Biol. 2019, 57, 412-423. [CrossRef] [PubMed]

32. Gabrielli, B.G.; Sarcevic, B.; Sinnamon, J.; Castellano, W.M.; Wang, X.Q.; Ellem, K.A. A cyclin D-Cdk4 activity required for G2 phase cell cycle progression is inhibited in ultraviolet radiation-induced G2 phase delay. J. Biol. Chem. 1999, 274, 13961-13969. [CrossRef] [PubMed]

33. Zhou, C.; Ma, J.; Su, M.; Shao, D.; Zhao, J.; Zhao, T.; Song, Z.; Meng, Y.; Jiao, P. Down-regulation of STAT3 induces the apoptosis and G1 cell cycle arrest in esophageal carcinoma ECA109 cells. Cancer Cell Int. 2018, 18, 53. [CrossRef] [PubMed]

34. Wang, H.; Deng, J.; Ren, H.Y.; Jia, P.; Zhang, W.; Li, M.Q.; Li, S.W.; Zhou, Q. HSTAT3 influences the characteristics of stem cells in cervical carcinoma. Oncol. Lett. 2017, 14, 2131-2136. [CrossRef] [PubMed] 